\title{
Qiliqiangxin Attenuates Phenylephrine- Induced Cardiac Hypertrophy through Downregulation of MiR-199a-5p
}

\author{
Haifeng Zhang ${ }^{\mathrm{a}}$ Shanshan Lia Qiulian Zhou ${ }^{\mathrm{b}}$ Qi Sun ${ }^{\mathrm{b}}$ Shutong Shen ${ }^{\mathrm{a}}$ \\ Yanli Zhou ${ }^{a}$ Yihua Beib,c Xinli Lia \\ aDepartment of Cardiology, The First Affiliated Hospital of Nanjing Medical University, Nanjing, \\ ${ }^{b}$ Regeneration and Ageing Lab, School of Life Science, Shanghai University, Shanghai, 'Shanghai Key \\ Laboratory of Bio-Energy Crops, School of Life Science, Shanghai University, Shanghai, China
}

\section{Key Words}

Qiliqiangxin • Cardiomyocytes • Hypertrophy • Phenylephrine • MiR-199a-5p

\begin{abstract}
Background/Aims: Qiliqiangxin (QL), a traditional Chinese medicine, has long been used to treat chronic heart failure. Previous studies demonstrated that QL could prevent cardiac remodeling and hypertrophy in response to hypertensive or ischemic stress. However, little is known about whether QL could modulate cardiac hypertrophy in vitro, and (if so) whether it is through modulation of specific hypertrophy-related microRNA. Methods: The primary neonatal rat ventricular cardiomyocytes were isolated, cultured, and treated with phenylephrine (PE, 50 $\mu \mathrm{mol} / \mathrm{L}, 48 \mathrm{~h}$ ) to induce hypertrophy in vitro, in the presence or absence of pretreatment with $\mathrm{QL}(0.5 \mu \mathrm{g} / \mathrm{ml}, 48 \mathrm{~h})$. The cell surface area was determined by immunofluorescent staining for $\alpha$-actinin. The mRNA levels of hypertrophic markers including atrial natriuretic peptide (ANP), brain natriuretic peptide (BNP), and $\beta$-myosin heavy chain (MYH7) were assayed by qRT-PCRs. The protein synthesis of cardiomyocytes was determined by the protein/DNA ratio. The miR199a-5p expression level was quantified in PE-treated cardiomyocytes and heart samples from acute myocardial infarction (AMI) mouse model. MiR-199a-5p overexpression was used to determine its role in the anti-hypertrophic effect of QL on cardiomyocytes. Results: PE induced obvious enlargement of cell surface in cardiomyocytes, paralleling with increased ANP, BNP, and MYH7 mRNA levels and elevated protein/DNA ratio. All these changes were reversed by the treatment with QL. Meanwhile, miR-199a-5p was increased in AMI mouse heart tissues. Of note, the increase of miR-199a-5p in PE-treated cardiomyocytes was reversed by the treatment with QL. Moreover, overexpression of miR-199a-5p abolished the anti-hypertrophic effect of QL on cardiomyocytes. Conclusion: QL prevents PE-induced cardiac hypertrophy. MiR-199a$5 p$ is increased in cardiac hypertrophy, while reduced by treatment with QL. miR-199a-5p suppression is essential for the anti-hypertrophic effect of QL on cardiomyocytes.
\end{abstract}




\section{Cellular Physiology Cell Physiol Biochem 2016;38:1743-1751 \begin{tabular}{l|l} 
and Biochemistry Published online: May 09, 2016 & $\begin{array}{l}\text { (c) } 2016 \text { The Author(s). Published by S. Karger AG, Basel } \\
\text { www.karger.com/cpb }\end{array}$
\end{tabular} \\ Zhang et al.: Qiliqiangxin Attenuates Cardiac Hypertrophy}

\section{Introduction}

Cardiac hypertrophy, mainly featured by cardiomyocyte enlargement, a wave of apoptosis, and re-activation of fetal genes, is an adaptive response to different stimuli like ischemic heart disease, hypertension, and cardiomyopathy. Although initially compensatory, prolonged cardiac hypertrophy frequently leads to cardiac dysfunction, heart failure, and even sudden death [1-5].

Qiliqiangxin (QL), a specific traditional Chinese medicine extracted from 11 distinct herbs (e.g. ginseng radix et rhizoma, astragali radix, aconiti lateralis radix preparata, semen descurainiae lepidii, etc), was approved by China Food and Drug Administration for the treatment of heart failure in 2004 [6]. A multicenter, randomized, double-blind, placebo-controlled study from our group demonstrated that on a background of standard treatment, chronic heart failure patients with a treatment of QL for 12 weeks had a greater reduction in the plasma level of N-terminal pro-B-type natriuretic peptide (NT-proBNP) [7]. Additionally, in spontaneous hypertension or transverse aorta constriction (TAC) experimental murine models, QL was proved to be effective to preserve cardiac function, reduce cardiac hypertrophy and remodeling, and improve mitochondrial function [8-10]. Also, it was demonstrated by our group that QL protected against cardiac remodeling after experimental myocardial infarction (MI) or ischemia-reperfusion injury (IRI) via the activation of peroxisome proliferator-activated receptor- $\gamma$ (PPAR- $\gamma$ ) and mTOR, respectively $[11,12]$. Although a limited number of in vitro studies revealed that QL could enhance the mitochondrial biogenesis in cardiomyocytes, and also inhibit the differentiation of cardiac fibroblasts $[13,14]$, the mechanism underlying the protective effect of QL against cardiac hypertrophy still remains elusive.

MicroRNAs (miRNAs, miRs) are a class of highly conserved small non-coding RNAs of 18-25 nucleotides in length that regulate posttranscriptional gene expressions [15]. MiRNAs participate in the control of cardiac physiology (morphogenesis, heart growth, and heart muscle contraction) [16-18], and also play key roles in the development of cardiac hypertrophy and heart failure [19-22]. Previous studies demonstrated an increase in miR199a-5p expression during cardiac hypertrophy in hypertensive experimental models [2325]. Moreover, miR-199a-5p is essential for the maintenance of cardiomyocyte cell size during hypertrophy, suggesting miR-199a-5p as a hypertrophy-related miRNA [26]. However, little is known about whether QL could modulate cardiac hypertrophy in vitro, and (if so) whether it is through modulation of specific hypertrophy-related miRNA.

In this study, we showed that QL prevents phenylephrine (PE)-induced cell enlargement in cardiomyocytes. Especially, the protective effect of QL against cardiac hypertrophy is dependent on the inhibition of miR-199a-5p.

\section{Materials and Methods}

Neonatal rat cardiomyocyte isolation, culture, and treatment

The primary neonatal rat ventricular cardiomyocytes were isolated from 1- to 3-day old SpragueDawley rats. Briefly, ventricles were dissected, washed, and finely minced in 1x ADS buffered saline solution (10x ADS 200 ml: NaCl 13.6 g, HEPES 9.52 g, Na ${ }_{2} \mathrm{HPO}_{4} 0.276$ g, Glucose 1.2 g, KCl 0.8 g, $\mathrm{MgSO}_{4} 0.0102$ g, $\mathrm{H}_{2} \mathrm{O}$ $200 \mathrm{ml}, \mathrm{pH} 7.35 \sim 7.45$ ). Tissues were then digested in a series of incubations at $37^{\circ} \mathrm{C}$ in $1 \mathrm{x}$ ADS-buffered saline solution containing $0.6 \mathrm{mg} / \mathrm{ml}$ trypsin (Sigma, St. Louis, MO, USA) and $0.4 \mathrm{mg} / \mathrm{ml}$ collagenase type II (Worthington, Lakewood, NJ, USA). After centrifugation, cells were resuspended in high-glucose Dulbecco's modified Eagle's medium (DMEM) (Gibco, Pasadena, CA, USA) supplemented with 10\% foetal bovine serum (FBS) (Gibco, Pasadena, CA, USA), 5\% horse serum (Hyclone, Logan, UT, USA), 1\% penicillin-streptomycin, and 0.1 mM 5'-Bromo-2'-Deoxyuridine (BrdU) (Sigma, St. Louis, MO, USA). The cells were then plated in $10 \mathrm{mg} / \mathrm{ml}$ gelatin (Sigma, St. Louis, MO, USA)-coated different culture dishes according to the specific experimental requirements.

After serum starvation for 6-8 h, the primary cardiomyocytes were treated for $48 \mathrm{~h}$ with $50 \mu \mathrm{mol} / \mathrm{L}$ of PE (Sigma, St. Louis, MO, USA) to induce hypertrophy in vitro, in the presence or absence of pretreatment KARGER 


\section{Cellular Physiology Cell Physiol Biochem 2016;38:1743-1751 and Biochemistry Published online: May 09, $2016 \quad \begin{aligned} & \text { DOI: 10.1159/000443113 } \\ & \text { (c) 2016 The Author(s). Published by S. Karger AG, Basel } \\ & \text { ww.karger.com/cpb }\end{aligned}$ \\ Zhang et al.: Qiliqiangxin Attenuates Cardiac Hypertrophy}

with QL $(0.5 \mu \mathrm{g} / \mathrm{ml}, 48 \mathrm{~h})$. QL was provided by Shijiazhuang Yiling Pharmaceutical Co., Ltd. (Shijiazhuang, Hebei, China). To further investigate whether the role of QL on cardiomyocyte hypertrophy is related to miR-199a-5p, cells were first treated with QL $(0.5 \mu \mathrm{g} / \mathrm{ml}, 48 \mathrm{~h})$, and then transfected with miR-199a-5p mimics or negative controls (NC-mimics) using Lipofectamine 2000 (Invitrogen, MA, USA). Eight hours after transfection, cells were treated with $50 \mu \mathrm{mol} / \mathrm{L}$ of PE for the next $48 \mathrm{~h}$, and finally collected for further analysis.

\section{Immunofluorescent staining for $\alpha$-actinin and cell size determination}

The cell size of cardiomyocytes was determined using immunofluorescent staining for $\alpha$-actinin. After treatment, cells were washed with PBS, fixed in 4\% paraformaldehyde (PFA) for 20 min, and blocked with $10 \%$ goat serum in PBS for $1 \mathrm{~h}$ at room temperature. Cells were then incubated with anti- $\alpha$-actinin antibody (Sigma, St. Louis, MO, USA) at 1:500 overnight. After three times of washes with PBS, cells were incubated with Cy3-AffiniPure goat anti-mouse IgG secondary antibody (Jackson ImmunoResearch, West Grove, PA, USA) coupled with DAPI. Finally, the cell images were taken in a Nikon eclipse Ti microscope and the cell surface area was analyzed using software ImageJ Launcher.

Quantitative reverse transcription polymerase chain reactions ( $q R T-P C R s$ )

Total RNA was extracted from cardiomyocytes or heart samples using miRNeasy Mini Kit (Tiangen, Beijing, China). The cDNA was synthesized using Bio-Rad iScript ${ }^{\mathrm{TM}}$ cDNA Synthesis Kit. The mRNA levels of atrial natriuretic peptide (ANP), brain natriuretic peptide (BNP), and $\beta$-myosin heavy chain (MYH7), were quantified using Takara SYBR Premix Ex Taq ${ }^{\text {TM }}$ (Tli RNaseH Plus, Takara, Tokyo, Japan) in the ABI-7900 Real-Time PCR Detection System. GAPDH was used for normalization. For miRNA quantification, the BulgeLoop $^{\mathrm{TM}}$ miRNA qPCR Primer Set (RiboBio, Guangzhou, China) was used to determine the expression level of miR-199a-5p with Takara SYBR Premix Ex Taq ${ }^{\text {TM }}$ in the ABI-7900 Real-Time PCR Detection System. U6 was used as an internal normalized reference. The primer sequences (forward and reverse) used in this study are listed as follows: ANP: CTC CCA GGC CAT ATT GGAG, TCC AGG TGG TCT AGC AGGTT; BNP: TGG GAA GTC CTA GCC AGT CTC, TCT GAG CCA TTT CCT CTGAC; MYH7: GGA TGA CGT TAC CTC CAACA, GTG TCT CCT CAG CCT TGCTC; GAPDH: GGC ACA GTC AAG GCT GAG AATG, ATG GTG GTG AAG ACG CCA GTA. The relative expression level for each gene or miRNA was calculated using the $2^{-\Delta \Delta C \mathrm{t}}$ method.

\section{Protein/DNA ratio of cardiomyocytes}

The cardiomyocytes were divided into two identical groups with the same cell identity. One group was used for total protein collection using RIPA buffer (Beyotime Institute of Biotechnology, Nantong, China). The total protein concentration was then determined using BCA Protein Assay Kit (Thermo Fisher, Waltham, MA, USA) on a microplate reader (Biotek synergy). Meanwhile, total RNA-free DNA was extracted from the other group using DNeasy Mini Kit (Qiagen, Hilden, Germany). The DNA concentration was analyzed using Nanodrop 2000 spectrophotometer (Thermo scientific). The protein/DNA ratio of cardiomyocytes was presented by the total protein concentration divided with the DNA concentration.

\section{Acute myocardial infarction mouse model}

Eight-week old male C57BL/6 mice were purchased from Nanjing University (Nanjing, China), and maintained in a temperature-controlled room on a $12 \mathrm{~h} / 12 \mathrm{~h}$ light/dark cycle. All procedures with animals were in accordance with guidelines on the use and care of laboratory animals for biomedical research published by National Institutes of Health (No. 85-23, revised 1996). The permanent ligation of left anterior descending coronary artery (LAD) was performed to induce acute myocardial injury (AMI) as previously described [27]. In brief, mice were anesthetized with ketamine and sevoflurane. The left anterior descending coronary artery was ligated about $2 \mathrm{~mm}$ under the left auricle using 7-0 silk sutures. Twenty-four hours after ligation, mice were sacrificed and heart tissues were collected for further analysis.

\section{Statistical analysis}

All data were expressed as mean \pm SEM. The statistical significance was assessed using one-way ANOVA for multiple-group comparisons followed by Bonferroni's post hoc test. Differences between groups were analyzed using unpaired, two-tailed Student's t test. A value of $p<0.05$ was considered statistically significant. 


\section{Cellular Physiology Cell Physiol Biochem 2016;38:1743-1751 \begin{tabular}{l|l} 
and Biochemistry & DOI: 10.1159/000443113 \\
Published online: May 09, 2016 & $\begin{array}{l}\text { C } 2016 \text { The Author(s). Published by S. Karger AG, Basel } \\
\text { www.karger.com/cpb }\end{array}$
\end{tabular} \\ Zhang et al.: Qiliqiangxin Attenuates Cardiac Hypertrophy}

\section{Results}

QL reverses phenylephrine-induced cardiomyocyte hypertrophy

To investigate whether QL attenuates cardiac hypertrophy in vitro, we induced the hypertrophy of primary cardiomyocytes by PE $(50 \mu \mathrm{mol} / \mathrm{L}, 48 \mathrm{~h})$, in the presence or absence of pretreatment with QL $(0.5 \mu \mathrm{g} / \mathrm{ml}, 48 \mathrm{~h})$. As one of the most potent hypertrophic stimuli known, PE induced obvious enlargement of cardiomyocytes as measured by cell surface labelled with $\alpha$-actinin (Fig. 1A). Meanwhile, the expressions of hypertrophic markers, including ANP, BNP, and MYH7, were consistently increased after treatment with PE (Fig. 1B). The protein synthesis of cardiomyocytes, as determined by the protein/DNA ratio, was also elevated by treatment with PE (Fig. 1C). Interestingly, PE-induced cardiomyocyte enlargement and the increase in hypertrophic markers (ANP, BNP, and MYH7) and protein/ DNA ratio, were markedly reversed by treatment with QL (Fig. 2A-C), indicating that QL was protective against PE-induced cardiac hypertrophy.

MiR-199a-5p is increased during cardiac hypertrophy, while reduced by treatment with $Q L$

Previous studies reported that miR-199a-5p was upregulated during cardiachypertrophy in hypertensive experimental models [23-26]. In addition to hypertensive stimulus, cardiac hypertrophy can also be induced by other forms of stress such as ischemic heart disease [23-26]. Thus, we continued to investigate whether miR-199a-5p could be modified in these pathological conditions. First, we investigated the expression of miR-199a-5p in AMI experimental model treated with QL that we have previously reported [12]. Interestingly, miR-199a-5p was markedly increased in the hearts suffered from AMI adverse remodeling, while the induced expression of miR-199a-5p was efficiently reversed by treatment with QL (Fig. 3A). After that, we sought to investigate whether miR-199a-5p was modulated in PE-induced cardiomyocyte hypertrophy in vitro. Similarly, miR-199a-5p was upregulated

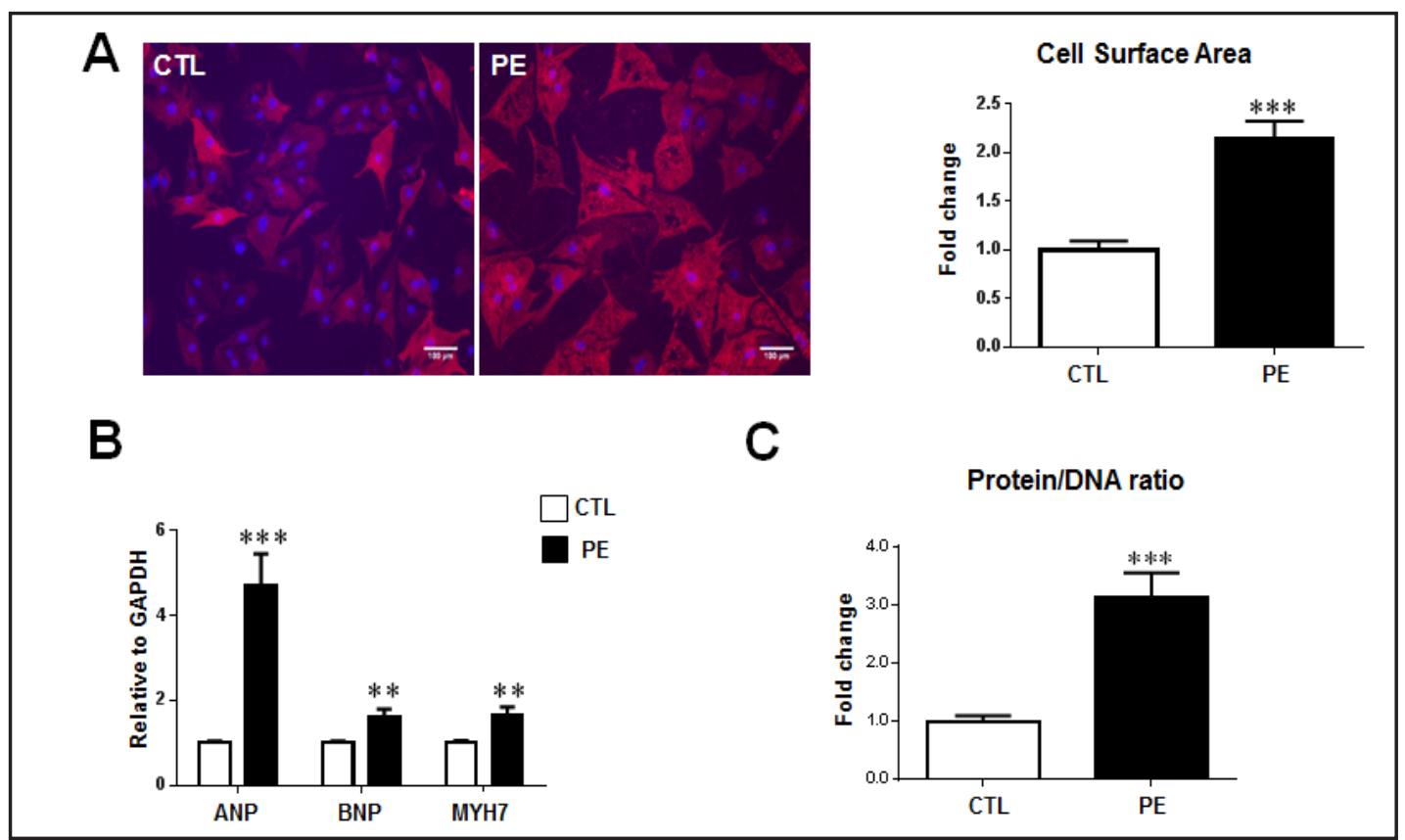

Fig. 1. Phenylephrine induces the hypertrophy of primary cardiomyocytes in vitro. The neonatal rat cardiomyocytes were isolated and treated with phenylephrine (PE, $50 \mu \mathrm{mol} / \mathrm{L}, 48 \mathrm{~h}$ ) to induce cardiac hypertrophy in vitro. (A) The cell surface of cardiomyocytes was determined using immunolabelling for $\alpha$-actinin (red) $(n=6)$. Nucleus was counter stained with DAPI (blue). Scale bar $=100 \mu \mathrm{m}$. (B) The mRNA levels of ANP, BNP, and MYH7 were assayed with real-time PCR $(n=6)$. (C) The protein/DNA ratio was determined to measure the protein synthesis of cardiomyocytes $(\mathrm{n}=6){ }^{*}, P<0.05 ;{ }^{* *}, P<0.01$; ***, $P<0.001$. 


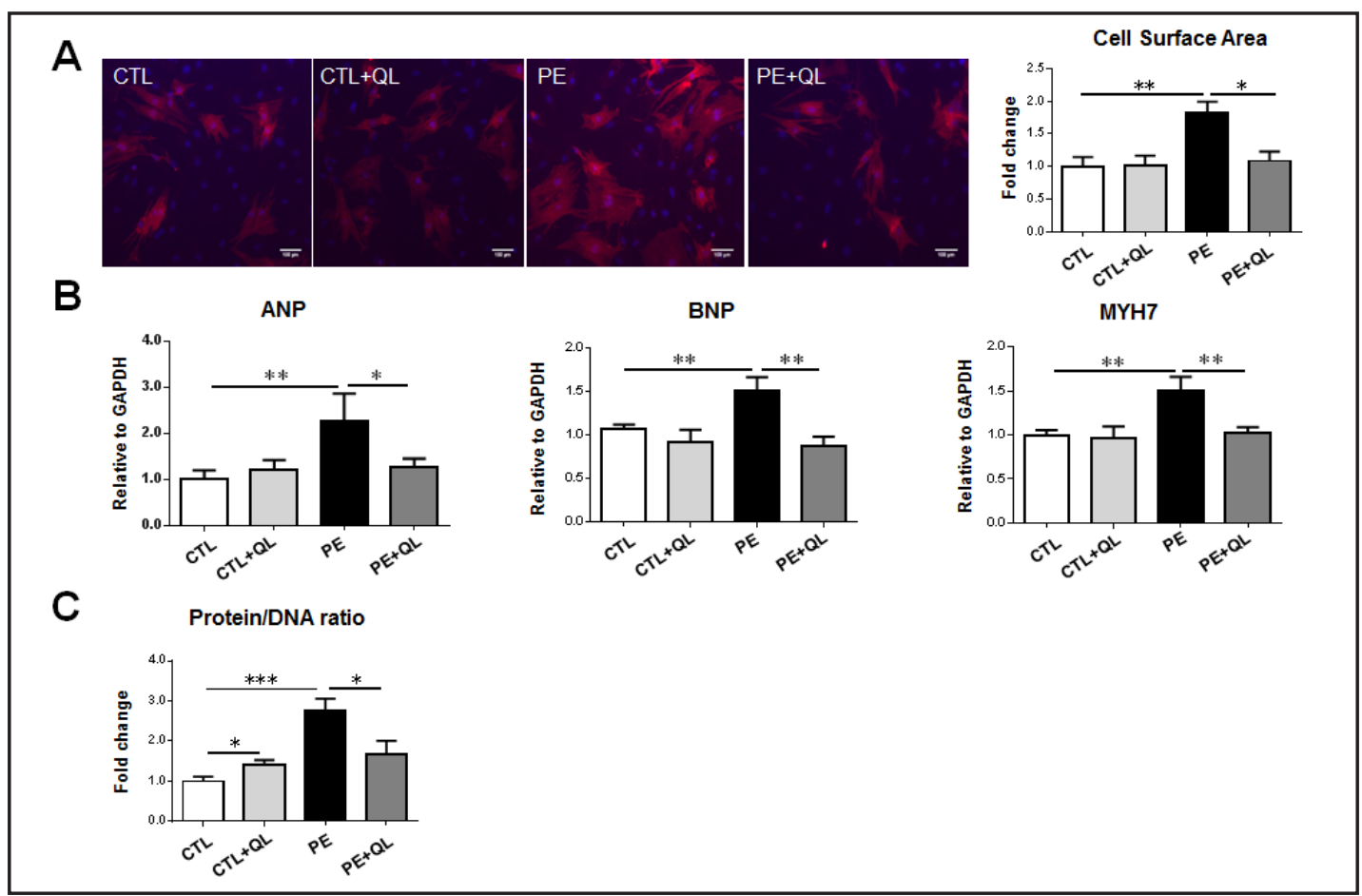

Fig. 2. Qiliqiangxin reverses phenylephrine-induced cardiac hypertrophy. The neonatal rat cardiomyocytes were pretreated with Qiliqiangxin (QL, $0.5 \mu \mathrm{g} / \mathrm{mL}, 48 \mathrm{~h}$ ) followed by treatment with phenylephrine (PE, 50 $\mu \mathrm{mol} / \mathrm{L}, 48 \mathrm{~h}$ ). (A) The cell surface of cardiomyocytes was determined using immunolabelling for $\alpha$-actinin (red) $(n=6)$. Nucleus was counter stained with DAPI (blue). Scale bar $=100 \mu \mathrm{m}$. (B) The mRNA levels of ANP, BNP, and MYH7 were assayed with real-time PCR $(n=6)$. (C) The protein/DNA ratio was determined to measure the protein synthesis of cardiomyocytes $(\mathrm{n}=6)$. $^{*}, P<0.05$; ${ }^{* *}, P<0.01$; ***, $P<0.001$.

\section{A}

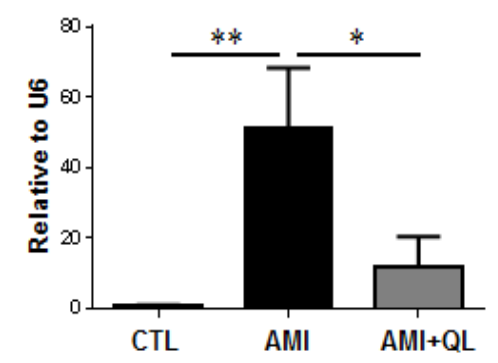

B

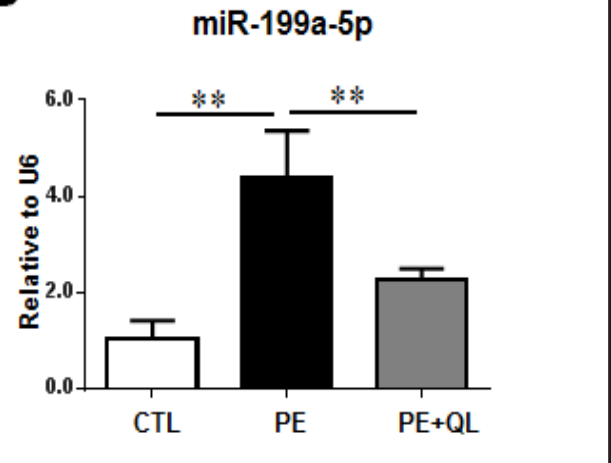

Fig. 3. miR-199a-5p is increased in cardiac hypertrophy, while reduced after treatment with Qiliqiangxin. (A) The miR-199a-5p expression level in experimental acute myocardial infarction (AMI) mouse model in the presence or absence of Qiliqiangxin (QL) treatment $(n=4)$. (B) The miR-199a-5p expression level in phenylephrine (PE)-induced hypertrophic cardiomyocytes in the presence or absence of QL treatment $(\mathrm{n}=$ 6). * $P<0.05$; **, $P<0.01$; *** $P<0.001$.

in PE-treated cardiomyocytes, which was however reversed by treatment with QL (Fig. 3B). These data provide evidence that miR-199a-5p is significantly upregulated in cardiac hypertrophy in response to different stimuli in vivo and in vitro. Moreover, the protective effect of QL against cardiac hypertrophy is accompanied by an inhibition of miR-199a-5p. 


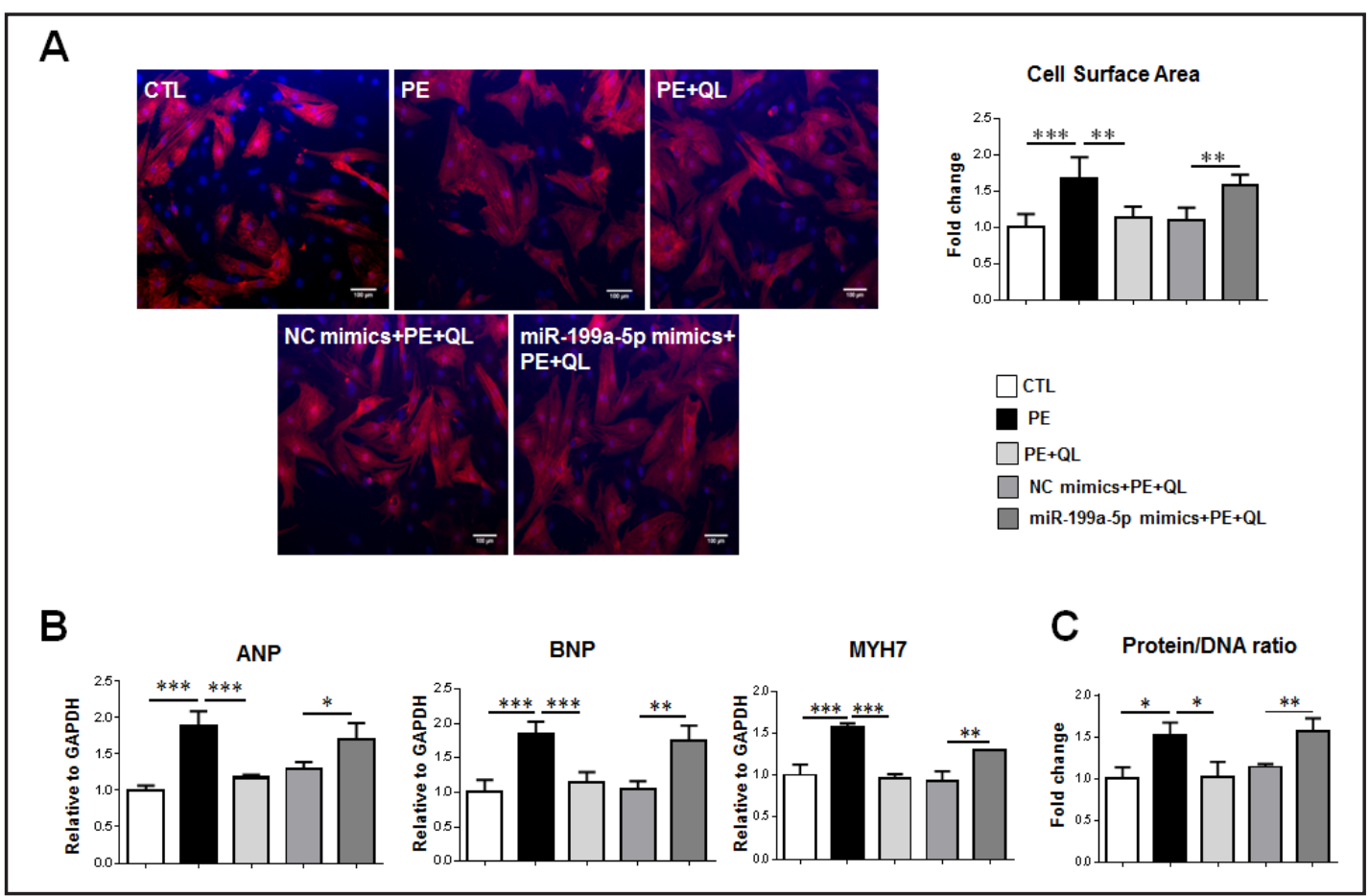

Fig. 4. Overexpression of miR-199a-5p abolishes the anti-hypertrophic effect of Qiliqiangxin on cardiomyocytes. The neonatal rat cardiomyocytes were pretreated with Qiliqiangxin (QL, $0.5 \mu \mathrm{g} / \mathrm{mL}, 48 \mathrm{~h}$ ), and then transfected with miR-199a-5p mimics or negative controls (NC-mimics) for $8 \mathrm{~h}$ before phenylephrine (PE) stimulation. (A) The cell surface of cardiomyocytes was determined using immunolabelling for $\alpha$-actinin (red) $(n=6)$. Nucleus was counter stained with DAPI (blue). Scale bar $=100 \mu \mathrm{m}$. (B) The mRNA levels of ANP, BNP, and MYH7 were assayed with real-time PCR $(n=6)$. (C) The protein/DNA ratio was determined to measure the protein synthesis of cardiomyocytes $(\mathrm{n}=6)$. $^{*}, P<0.05$; **, $P<0.01$; ***, $P<0.001$.

\section{MiR-199a-5p suppression is essential for the protective effect of QL against cardiomyocyte} hypertrophy

To further examine whether the protective effect of QL on hypertrophic cardiomyocytes was related to the inhibition of miR-199a-5p, we first treated the primary cardiomyocytes with QL for $48 \mathrm{~h}$, and then transfected the cells with miR-199a-5p mimics or miRNA negative control (NC mimics) for $8 \mathrm{~h}$ before PE induction. Our data showed that miR-199a-5p mimics could efficiently abolish the protective effect of QL against cardiomyocyte enlargement (Fig. 4A), with increased expressions of hypertrophic markers (ANP, BNP, and MYH7) and elevated protein/DNA ratio, as compared with QL-treated hypertrophic cardiomyocytes transfected with NC mimics (Fig. 4B and 4C). These data clearly indicate that the inhibition of miR-199a$5 p$ is necessary for the protective effect of QL on hypertrophic cardiomyocytes.

\section{Discussion}

Cardiac hypertrophy remains the major risk factor for heart failure, which represents one of the leading causes of hospitalization and death in aged population [28]. QL was previously demonstrated to be effective to reduce the plasma NT-proBNP level in patients with heart failure [7], and to attenuate cardiac remodeling and hypertrophy in different animal models [8-12, 29, 30]. However, few studies were conducted to explore the role of QL in cardiac hypertrophy in a cellular model. In this study, we demonstrated for the first time that QL protected cardiomyocytes from PE-induced hypertrophy, which was associated with the inhibition of miR-199a-5p.

\section{KARGER}




\section{Cellular Physiology Cell Physiol Biochem 2016;38:1743-1751 \\ and Biochemistry \begin{tabular}{l|l} 
DOI: 10.1159/000443113 & $\begin{array}{l}\text { (c) 2016 The Author(s). Published by S. Karger AG, Basel } \\
\text { www.karger.com/cpb }\end{array}$
\end{tabular} \\ Zhang et al.: Qiliqiangxin Attenuates Cardiac Hypertrophy}

Several molecular mechanisms, including the downregulated TNF- $\alpha /$ IL-10 ratio [6], inhibition of angiotensin II (AngII) type 1 receptor and activation of ErbB receptors [10], increased AMPK/PGC- $1 \alpha$ axis and NRG-1/Akt signaling $[9,29]$, and enhanced PPAR- $\gamma$ and mTOR activation $[11,12]$, were reported to be responsible for the protective effect of QL against cardiac remodeling and hypertrophy. Different from transcription factors and protein molecules, miRNAs are a class of single strand and non-coding small RNAs that can target a variety of genes, thus forming a complex signaling network in almost all biological processes [31]. Here we found that miR-199a-5p, a hypertrophy-related miRNA, was significantly increased in PE-induced hypertrophic cardiomyocytes. Importantly, QL effectively prevented cardiomyocyte hypertrophy, which was accompanied by a downregulation of miR-199a-5p, indicating a potential relation between the anti-hypertrophic effect of QL and the inhibition of miR-199a-5p expression.

MiR-199a-5p, which is principally expressed in cardiomyocytes, was shown to be upregulated during cardiac hypertrophy [23-25]. Moreover, overexpression of miR-199a-5p increased the cell size of cardiomyocytes, while downregulation of miR-199a-5p reduced PEinduced hypertrophy in cardiomyocytes [26]. Based on these studies, we decided to clarify whether the anti-hypertrophic effect of QL was related to the regulation of miR-199a-5p. Interestingly, overexpression of miR-199a-5p significantly abolished the anti-hypertrophic effect of QL in cardiomyocytes, as represented by enlarged cell size, increased hypertrophy markers, and enhanced protein synthesis. These data provide strong evidence that the inhibition of miR-199a-5p is essential for the protective effect of QL against hypertrophy in cardiomyocytes.

It is widely accepted that cardiac hypertrophy can be associated with different pathologies [5]. Our group has previously reported that QL was effective to prevent cardiac dysfunction and remodeling in animal models of AMI [12]. As expected, we found that miR199a-5p was markedly upregulated in ischemic hearts of AMI mice, while downregulated after the treatment with QL. Increasing evidence indicates that the aberrantly expressed miRNAs in pathologies could be used as potential biomarkers for disease diagnosis and prognosis prediction [32-35]. For those diseases in which miRNA(s) was significantly upregulated, antagomiR(s) that could inhibit specific miRNA expression(s) in vivo may represent a novel therapeutic strategy [36]. In line of these considerations, downregulation of miR-199a-5p might be beneficial for the treatment of cardiac hypertrophy, which is at least in part responsible for the protective effect of QL.

Several limitations should be highlighted for the present study. Firstly, the previously reported target genes of miR-199a-5p such as Hif- $1 \alpha$, as well as novel target genes of miR199a-5p, should be identified to further clarify the molecular mechanisms by which QL protects against cardiac hypertrophy. Secondly, how QL inhibits miR-199a-5p is unclear. Thirdly, since QL is composed of 11 diverse herbal medicine ingredients, which compound(s) contributes to the downregulation of miR-199a-5p during cardiac hypertrophy needs to be further investigated.

In conclusion, the present study provides evidence that QL prevents PE-induced hypertrophy in cardiomyocytes. Downregulation of miR-199a-5p is essential for the antihypertrophic effect of QL. The mechanism for the protective effect of QL against cardiac hypertrophy warrants further investigation.

\section{Acknowledgments}

This work was supported by the grants from National Natural Science Foundation of China (81370332 and 81170201 to XL Li; 81400647 to Y Bei), the Priority Academic Program Development of Jiangsu Higher Education Institutions (PAPD20102013 to XL Li), the National Basic Research Program of China (973 Program, Grant no.2012CB518606). $\mathrm{Dr} \mathrm{XL} \mathrm{Li}$ is an Associate Fellow at the Collaborative Innovation Center for Cardiovascular Disease Translational Medicine. 


\section{Cellular Physiology Cell Physiol Biochem 2016;38:1743-1751 and Biochemistry \begin{tabular}{l|l} 
DOI: 10.1159/000443113 & (c) 2016 The Author(s). Published by S. Karger AG, Basel \\
www.karger.com/cpb
\end{tabular} \\ Zhang et al.: Qiliqiangxin Attenuates Cardiac Hypertrophy}

\section{Disclosure Statement}

Dr. Xinli Li received research grants from Shijiazhuang Yiling Pharmaceutical Co., Ltd. All other authors have reported that they have no relationships to disclose.

\section{References}

1 Hunter JJ, Chien KR: Signaling pathways for cardiac hypertrophy and failure. N Engl J Med 1999;341:12761283.

2 do Império GE, Ramos IP, Santiago LA, Pereira GF, dos Santos Almeida NA, Fuziwara CS, Pazos-Moura CC, Kimura ET, Olivares EL, Ortiga-Carvalho TM: The impact of a non-functional thyroid receptor beta upon triiodotironine-induced cardiac hypertrophy in mice. Cell Physiol Biochem 2015;37:477-490.

3 Yin K, Zhao L, Feng D, Ma W, Liu Y, Wang Y, Liang J, Yang F, Bi C, Chen H, Li X, Lu Y, Cai B: Resveratrol attenuated low ambient temperature-induced myocardial hypertrophy via inhibiting cardiomyocyte apoptosis. Cell Physiol Biochem 2015;35:2451-2462.

4 Wang YS, Zhou J, Hong K, Cheng XS, Li YG: MicroRNA-223 displays a protective role against cardiomyocyte hypertrophy by targeting cardiac troponin I-interacting kinase. Cell Physiol Biochem 2015;35:1546-1556.

5 Lin Y, Zhang X, Wang L, Zhao Y, Li H, Xiao W, Xu C, Liu J: Polyamine depletion attenuates isoproterenolinduced hypertrophy and endoplasmic reticulum stress in cardiomyocytes. Cell Physiol Biochem 2014;34:1455-1465.

6 Xiao H, Song Y, Li Y, Liao YH, Chen J: Qiliqiangxin regulates the balance between tumor necrosis factoralpha and interleukin-10 and improves cardiac function in rats with myocardial infarction. Cell Immunol 2009;260:51-55.

7 Li X, Zhang J, Huang J, Ma A, Yang J, Li W, Wu Z, Yao C, Zhang Y, Yao W, Zhang B, Gao R, Efficacy, Safety of Qili Qiangxin Capsules for Chronic Heart Failure Study G: A multicenter, randomized, double-blind, parallelgroup, placebo-controlled study of the effects of qili qiangxin capsules in patients with chronic heart failure. J Am Coll Cardiol 2013;62:1065-1072.

8 Ye Y, Gong H, Wang X, Wu J, Wang S, Yuan J, Yin P, Jiang G, Li Y, Ding Z, Zhang W, Zhou J, Ge J, Zou Y: Combination treatment with antihypertensive agents enhances the effect of qiliqiangxin on chronic pressure overload-induced cardiac hypertrophy and remodeling in male mice. J Cardiovasc Pharmacol 2015;65:628-639.

9 Zhang J, Wei C, Wang H, Tang S, Jia Z, Wang L, Xu D, Wu Y: Protective effect of qiliqiangxin capsule on energy metabolism and myocardial mitochondria in pressure overload heart failure rats. Evid Based Complement Alternat Med 2013;2013:378298.

10 Zou Y, Lin L, Ye Y, Wei J, Zhou N, Liang Y, Gong H, Li L, Wu J, Li Y, Jia Z, Wu Y, Zhou J, Ge J: Qiliqiangxin inhibits the development of cardiac hypertrophy, remodeling, and dysfunction during 4 weeks of pressure overload in mice. J Cardiovasc Pharmacol 2012;59:268-280.

11 Zhou Y, Fang H, Lin S, Shen S, Tao L, Xiao J, Li X: Qiliqiangxin protects against cardiac ischemia-reperfusion injury via activation of the mtor pathway. Cell Physiol Biochem 2015;37:454-464.

12 Tao L, Shen S, Fu S, Fang H, Wang X, Das S, Sluijter JP, Rosenzweig A, Zhou Y, Kong X, Xiao J, Li X: Traditional chinese medication qiliqiangxin attenuates cardiac remodeling after acute myocardial infarction in mice. Sci Rep 2015;5:8374.

13 Lin S, Wu X, Tao L, Bei Y, Zhang H, Zhou Y, Shen S, Xiao J, Li X: The metabolic effects of traditional chinese medication qiliqiangxin on h9c2 cardiomyocytes. Cell Physiol Biochem 2015;37:2246-2256.

14 Zhou J, Jiang K, Ding X, Fu M, Wang S, Zhu L, He T, Wang J, Sun A, Hu K, Chen L, Zou Y, Ge J: Qiliqiangxin inhibits angiotensin ii-induced transdifferentiation of rat cardiac fibroblasts through suppressing interleukin-6. J Cell Mol Med 2015;19:1114-1121.

15 van Rooij E: The art of microrna research. Circ Res 2011;108:219-234.

16 Liu X, Xiao J, Zhu H, Wei X, Platt C, Damilano F, Xiao C, Bezzerides V, Bostrom P, Che L, Zhang C, Spiegelman BM, Rosenzweig A: Mir-222 is necessary for exercise-induced cardiac growth and protects against pathological cardiac remodeling. Cell Metab 2015;21:584-595.

17 Wang H, Bei Y, Shi J, Xiao J, Kong X: Non-coding rnas in cardiac aging. Cell Physiol Biochem 2015;36:16791687. 


\section{Cellular Physiology Cell Physiol Biochem 2016;38:1743-1751 \begin{tabular}{c|c|c|} 
DOI: 10.1159/000443113 & $\begin{array}{l}\text { O 2016 The Author(s). Published by S. Karger AG, Basel } \\
\text { www.karger.com/cpb }\end{array}$
\end{tabular} \\ Zhang et al.: Qiliqiangxin Attenuates Cardiac Hypertrophy}

18 Tao L, Bei Y, Zhou Y, Xiao J, Li X: Non-coding rnas in cardiac regeneration. Oncotarget 2015;6:42613-42622.

19 Huang S, Zou X, Zhu JN, Fu YH, Lin QX, Liang YY, Deng CY, Kuang SJ, Zhang MZ, Liao YL, Zheng XL, Yu XY, Shan ZX: Attenuation of microrna-16 derepresses the cyclins d1, d2 and e1 to provoke cardiomyocyte hypertrophy. J Cell Mol Med 2015;19:608-619.

20 Greco CM, Condorelli G: Epigenetic modifications and noncoding rnas in cardiac hypertrophy and failure. Nat Rev Cardiol 2015;12:488-497.

21 Wei L, Yuan M, Zhou R, Bai Q, Zhang W, Zhang M, Huang Y, Shi L: Microrna-101 inhibits rat cardiac hypertrophy by targeting rab1a. J Cardiovasc Pharmacol 2015;65:357-363.

22 Cheng Y, Ji R, Yue J, Yang J, Liu X, Chen H, Dean DB, Zhang C: Micrornas are aberrantly expressed in hypertrophic heart: Do they play a role in cardiac hypertrophy? Am J Pathol 2007;170:1831-1840.

23 Rane S, He M, Sayed D, Yan L, Vatner D, Abdellatif M: An antagonism between the akt and beta-adrenergic signaling pathways mediated through their reciprocal effects on mir-199a-5p. Cell Signal 2010;22:10541062.

24 Sayed D, Hong C, Chen IY, Lypowy J, Abdellatif M: Micrornas play an essential role in the development of cardiac hypertrophy. Circ Res 2007;100:416-424.

25 van Rooij E, Sutherland LB, Liu N, Williams AH, McAnally J, Gerard RD, Richardson JA, Olson EN: A signature pattern of stress-responsive micrornas that can evoke cardiac hypertrophy and heart failure. Proc Natl Acad Sci USA 2006;103:18255-18260.

26 Song XW, Li Q, Lin L, Wang XC, Li DF, Wang GK, Ren AJ, Wang YR, Qin YW, Yuan WJ, Jing Q: Micrornas are dynamically regulated in hypertrophic hearts, and mir-199a is essential for the maintenance of cell size in cardiomyocytes. J Cell Physiol 2010;225:437-443.

27 Tao L, Bei Y, Lin S, Zhang H, Zhou Y, Jiang J, Chen P, Shen S, Xiao J, Li X: Exercise training protects against acute myocardial infarction via improving myocardial energy metabolism and mitochondrial biogenesis. Cell Physiol Biochem 2015;37:162-175.

28 Xie M, Burchfield JS, Hill JA: Pathological ventricular remodeling: Therapies: Part 2 of 2. Circulation 2013;128:1021-1030.

29 Wang J, Zhou J, Ding X, Zhu L, Jiang K, Fu M, Wang S, Hu K, Ge J: Qiliqiangxin improves cardiac function and attenuates cardiac remodeling in rats with experimental myocardial infarction. Int J Clin Exp Pathol 2015;8:6596-6606.

30 Liu W, Chen J, Xu T, Tian W, Li Y, Zhang Z, Li W: Qiliqiangxin improves cardiac function in spontaneously hypertensive rats through the inhibition of cardiac chymase. Am J Hypertens 2012;25:250-260.

31 Farh KK, Grimson A, Jan C, Lewis BP, Johnston WK, Lim LP, Burge CB, Bartel DP: The widespread impact of mammalian micrornas on mrna repression and evolution. Science 2005;310:1817-1821.

32 Xiao J, Shen B, Li J, Lv D, Zhao Y, Wang F, Xu J: Serum microrna-499 and microrna-208a as biomarkers of acute myocardial infarction. Int J Clin Exp Med 2014;7:136-141.

33 Melman YF, Shah R, Danielson K, Xiao J, Simonson B, Barth A, Chakir K, Lewis GD, Lavender Z, Truong QA, Kleber A, Das R, Rosenzweig A, Wang Y, Kass DA, Singh JP, Das S: Circulating microrna-30d is associated with response to cardiac resynchronization therapy in heart failure and regulates cardiomyocyte apoptosis: A translational pilot study. Circulation 2015;131:2202-2216.

34 Li J, Xu J, Cheng Y, Wang F, Song Y, Xiao J: Circulating micrornas as mirrors of acute coronary syndromes: Miracle or quagmire? J Cell Mol Med 2013;17:1363-1370.

35 Xu T, Zhou Q, Che L, Das S, Wang L, Jiang J, Li G, Xu J, Yao J, Wang H, Dai Y, Xiao J: Circulating mir-21, mir378 , and mir-940 increase in response to an acute exhaustive exercise in chronic heart failure patients. Oncotarget DOI:10.18632/oncotarget.6966.

36 Li RC, Tao J, Guo YB, Wu HD, Liu RF, Bai Y, Lv ZZ, Luo GZ, Li LL, Wang M, Yang HQ, Gao W, Han QD, Zhang YY, Wang XJ, Xu M, Wang SQ: In vivo suppression of microrna-24 prevents the transition toward decompensated hypertrophy in aortic-constricted mice. Circ Res 2013;112:601-605. 